\title{
ESPACIO PÚBLICO, PROCESO AGRARIO Y CIUDADANÍA EN EL NORESTE DE GUANAJUATO
}

\author{
Jorge Uzeta
}

Resumen: En el noreste de Guanajuato se puede identificar actualmente una dinámica de apertura electoral sustentada en una participación individual ciudadanizada que ha marginado progresivamente a los grupos corporados representados por unidades ejidales. Teniendo como eje el municipio de Atarjea, en este trabajo se discute la relación de ambos procesos -el agrario y el político electoral - en la configuración del espacio público. Para ello resulta de enorme utilidad la noción de parentela como una opción mucho más flexible a la rígida idea de corporativismo campesino.

Palabras clave: Espacio público, ejido, ciudadanía, parentela, elecciones.

Enviado a dictamen: 18 de febrero de 2010

Aprobación: 08 de mayo de 2010

Revisiones: 1

Jorge Uzeta, doctor en Ciencias Sociales por El Colegio de Michoacán. Labora actualmente en el Centro de Estudios Antropológicos de El Colegio de Michoacán, Zamora, Michoacán. Temas de especialización: etnicidad, ritualidad otomí y poder. Correo electrónico: jorgeuzeta@colmich.edu.mx.
Abstract: In broad sense, in the noreast of Guanajuato is visible an electoral openness trough an individual citizenship participation who progressive margined corporate groups like the ejidos. Having the municipio of Atarjea like an axis, on this work I argument the relation between the two processes - the agrarian and the political electoral-on the configuration of public space. For the topic is very useful the notion of relatives like a more flexible option than the stiff idea of peasantry corporation.

Key words: Public space, ejido, citizenship, relatives, elections.

\section{El espacio público como problema ${ }^{1}$}

L a discusión acerca del espacio público refiere de una manera bastante compleja al surgimiento, desarrollo e interacción entre la sociedad civil, las vías de intercambio comercial y marcos legales bajo Estados constituidos. Como tal, es una categoría propia de la sociedad burguesa, impulsada tanto por la fuerza revolucionaria del capitalismo mercantil como por la opinión pública que emerge paralelamente a través de medios como la prensa (Habermas, 1991). Aunque producto de ese tipo de procesos históricos también puede identificarse puntualmente, en términos 
diacrónicos, con "un conjunto de mecanismos para tratar con los problemas colectivos" (Escalante, 1995: 35). En ambos casos el espacio público se encuentra asociado con derechos generales sintetizados en la capacidad de discutir y actuar socialmente, y con las trasformaciones que eso produce. Los sentidos de participación y pertenencia aparejados con aquellos derechos generales pueden equipararse fácilmente con nociones amplias de ciudadanía, irreductibles a actores políticos individuales.

No obstante, la asociación entre individuo y ciudadanía es uno de los referentes más poderosos de la democracia moderna, de hecho está en la base de los procesos electorales por los que, a través del voto libre y secreto, se expresa la voluntad mayoritaria. Sin embargo, las perspectivas que sugieren como intrínsecamente positiva la construcción de sociedades asentadas sobre derechos cívicos comunes e individuales donde antes predominaban principios jerárquicos y corporativos pasan de largo sobre un asunto relevante. Miradas históricas y antropológicas suelen mostrar que, lejos de tratarse de formas sociales mutuamente excluyentes, principios de ambos modelos llegan a coexistir y combinarse dando forma a sistemas de valores "que estructura[n] el espacio público, que le $\mathrm{da}[\mathrm{n}]$ forma y sentido, que decide[n] expectativas y tipos de relaciones" (Escalante, 1995: 42). En localidades y municipios con fuerte presencia indígena, o con una impronta campesina comprometida históricamente con la formación de comunidades ejidales, la creación de sentidos individuales y liberales de ciudadanía política genera tensiones que inciden en el perfil local del espacio público y, quizá más importante, que pueden debilitar las capacidades grupales para negociar o confrontar proyectos estatales impopulares.

Me interesa abordar este tipo de asuntos problematizando inicialmente sobre la construcción del espacio público en Atarjea, el más distante, desatendido y casi de menor densidad demográfica de los municipios serranos del noreste de Guanajuato (menos de 13 habitantes por $\mathrm{Km}^{2}$ ). Por una parte busco argumentar que el asunto está relacionado directamente con la formación de las redes políticas del agrarismo cardenista, con su crisis y también con la construcción liberal de ciudadanías y prácticas electorales; pero - por la otra- que no se trata de la simple sustitución de lógicas corporativas por otras de carácter individualista, sino de la azarosa reinterpretación de éstas últimas a partir de valores locales asociados con el parentesco.

Desde hace varios años etnógrafos interesados en lograr una mayor comprensión sobre los alcances políticos de los movimientos campesinos han señalado la necesidad de atender seriamente su "dinámica cultural" (Starn, 1991: 33). Estas posiciones han incorporado miradas inquisitivas sobre los espacios físicos, su simbolismo, sus formas de representación y de uso, destacando aquellos "donde las elites y los subalternos pueden rozar hombros", es decir, los ámbitos definidos no por el control de los poderosos sino por su "universalidad y accesibilidad" (Wilson, 2002: 94). En esos términos el espacio que resulta de las prácticas y relaciones de quienes lo viven puede asumirse como "un artefacto cultural de cohesión y conflicto social" (Zukin, 1991: 12), una connotación de lo "público" que supone la interlocución crítica ante la autoridad despersonalizada del Estado y, por lo mismo, de formación de responsabilidad y opinión pública (Habermas, 1991). ${ }^{2}$ En este caso es muy útil el señalamiento de Robotnikof (1997:21), para quien la idea de lo público es parte de la política en tanto que en ella se articulan históricamente y de manera compleja lo concerniente al "interés y utilidad común [...], lo visible y manifiesto, y lo abierto [...] y accesible".

Haciendo eco de esos "intereses comunes" se ha destacado la capacidad de los grupos subordinados para crear espacios en donde combaten las condiciones de desigualdad que los aquejan; al hacerlo dan forma a ciudadanías basadas en principios de "dignidad y autonomía" dirigidas al "disfrute colectivo de justicia 
social", trascendiendo la noción común asentada en los "derechos y obligaciones individuales ante un estado liberal" (Harvey, 2000: 49). De manera que la construcción de ciudadanías locales resulta paralela a la definición del espacio público, y éste último es el lugar en donde las identidades y el juego político se definen simultáneamente con respecto a la expresión, constatación y reinterpretación de discursos de poder. La misma Wilson analizaba estos asuntos a partir del peso público de las prácticas religiosas y de la subordinación casi estamental de la población indígena andina con la que trabajó.

En Atarjea la cuestión del espacio público ha pasado también por la influencia de ciertas prácticas religiosas realizadas fuera de los templos, sin embargo, ha sido la persistencia de demandas de justicia agraria sumadas a nociones arraigadas de autoridad personalista — a una cultura patriarcal, digamos-, lo que ha predominado en ese municipio al menos desde la década de 1920. Quienes lograron de origen un posicionamiento político en el municipio serrano que me interesa fueron los primeros peticionarios: patriarcas devenidos en líderes ejidales. Estos personajes se ganaron el apelativo local de "caciques" tanto por sus vínculos con destacados intermediarios regionales y por su capacidad para hacer favores y relaciones, como por el conocimiento adquirido de la tramitología y de los vericuetos administrativos obtenidos en el desempeño de distintos cargos en el ejido y en municipio. Prácticas y valores con incidencia en el espacio público.

Esas persistencias deben ser atendidas no por su aparente inflexibilidad sino por lo que de hecho ha demostrado tener de maleable a partir de su propia actualización; y es la noción de parentela, más que la de familia campesina — tan asociada aún con ideas de unidad política y productiva corporadas- la que resulta aquí de gran utilidad. Por tal debe entenderse a grupos unificados por un "sentimiento común de descendencia" sin ser "estrictamente" grupos corporados (Rhum, 2000: 391). ${ }^{3}$
Tomando prestada la definición que Fernando Salmerón utiliza sobre el parentesco, el sentido de parentela "cruza" el entramado social para regular no sólo el ámbito analíticamente identificado como privado sino también "para estructurar las relaciones en una arena pública incierta u hostil" (Salmerón, 2002: 35). Sin embargo, el afecto, la confianza y la legitimidad ganados dentro de la parentela siempre son frágiles por lo que se juega en cada caso y aún por los relevos generacionales. Aquí el sentimiento de afecto asociado comúnmente con el parentesco, sobre todo entre consanguíneos, es un elemento para la polarización de las diferencias o para la posible rearticulación política de la parentela; es también un contrapeso a la racionalidad de elección que otros autores han destacado en la formación de coaliciones políticas (Boissevain, 1974). Así, pese a la dificultad para identificar un "sentimiento común de descendencia”, éstas perspectivas pueden llevarnos a comprender con mayor profundidad la trascendencia política de los vínculos parentales trazados en los momentos álgidos y regionalmente militarizados del reparto agrario en el noreste de Guanajuato, punto nodal en la construcción del espacio público ligado al predominio de los ejidos. También nos puede ayudar a comprender lo que ocurre hoy en Atarjea frente a la apertura electoral y ante iniciativas estatales ajenas a los principios locales de justicia agraria.

\section{Diferentes espacios}

Para ubicar al noreste de Guanajuato, y a Atarjea en particular, se debe decir algo sobre la Sierra Gorda. Su calidad de región radica menos en la quebrada geografía compartida entre Querétaro, San Luis Potosí y Guanajuato, y más en la influencia de algunas redes de mercado y prácticas religiosas. Ambos asuntos son un buen punto de partida para abordar el tipo de relaciones involucradas en la formación del espacio público atarjense (ver mapa de La Sierra Gorda). 
Por lo que respecta a la primera, varios de los puntos del interior serrano, como los municipios de Xichú y Atarjea, lograron cierto desarrollo como "Mineros asociados" en el último tercio del siglo XIX con el de San Luis de la Paz. Si bien las relaciones entre estas poblaciones se encontraban obstaculizadas por la deplorable infraestructura en comunicaciones, la explotación de plata, plomo y mercurio logró generar un restringido entorno de poblaciones con perfiles productivos bastante definidos en torno de cada una de ellas. Para el caso específico de Atarjea unas estaban dedicadas a la proveeduría de maderas, barro y fuerza de trabajo necesaria para las actividades extractivas; otras, en su papel de haciendas renteras, eran productoras de granos, bestias de carga y diversos enceres. La conexión entre todas se realizaba a través de caminos de herradura y mercados semanales.

Esta organización productiva del espacio se enlazaba a su vez con la ciudad de Querétaro, en cuya amplia órbita interestatal destacarían y desaparecerían puntos de intercambio de perecederos, de abarrotes y de ganado, a partir de altibajos productivos vinculados con la variabilidad climática, con las múltiples tensiones políticas del siglo XIX y con los consecuentes movimientos de población. Ejemplo de ello son las localidades queretanas de Peña Miller, San Ciro y Jalpan, pero también la de Río Verde en la huasteca potosina.

El trazo de carreteras y caminos vecinales a partir de los años sesenta del siglo pasado - muchos en pésimo estado hasta hoy - no harían sino confirmar el dominio económico de Querétaro impulsando nuevos puntos de intercambio en las cercanías de la Sierra, entre otros el mercado de ganado en el municipio de Doctor Mora.

Por lo que respecta a las prácticas religiosas, justamente en los primeros años del siglo XX se verificó el hallazgo de una imagen del niño Jesús que eventualmente fue denominada con el nombre del Santo Niño de Jalpan. Encontrada en uno de los municipios de la zona luego de un desmonte realizado para habilitar tierras de cultivo, la imagen estuvo bajo el cuidado de particulares hasta que su creciente fama de milagrosa empujó a la intervención de la iglesia católica, que logró depositarla en la parroquia queretana de Jalpan, población que entonces despuntaba como un subcentro mercantil en el interior serrano.

La existencia de esta imagen no sólo dotó de cariz de santuario a aquella parroquia sino que también animó la organización de un circuito de peregrinaciones desde distintos municipios colindantes hacia el lugar para el festejo patronal cada enero, así como la circulación de una imagen idéntica a la venerada en un amplio radio de comunidades serranas. De manera que estos dos ciclos, uno de los márgenes regionales hacia el santuario de Jalpan para el día festivo, y otro que enlaza esa localidad con muchas comunidades rurales de la franja interestatal a través de la circulación de la imagen, han reforzado un espacio regional de intercambio simbólico y económico evitando a Querétaro como referente central. En la medida en que la imagen peregrina ha sido recibida con mayor boato en parroquias frecuentemente ubicadas en las cabeceras políticas, estos ciclos contribuyeron a fortalecer la preeminencia de las anteriores en el entorno territorial de sus respectivos municipios. A esto se debe agregar, al menos en Atarjea, celebraciones públicas básicamente de carácter municipal, como una muy nutrida representación de la aprehensión y crucifixión de Cristo durante la semana santa y el festejo a la virgen de Guadalupe en diciembre.

Sin embargo, en su momento estas fuerzas de configuración regional interestatal fueron políticamente reorientadas tanto por la influencia que tuvieron ciertos acontecimientos de carácter nacional en cada entidad (un buen ejemplo es la rebelión delahuertista de 1923), como por el movimiento de fuerzas sociales específicas de estas últimas. En Guanajuato podemos hablar de la quiebra minera de inicios del siglo XX y de los efectos de la exacerbada lucha ideológica y militar de su primera mitad, que incluye entre otras cosas los relevos constantes en el ejecutivo estatal y la guerra cristera. 
Aunque la exigencia de tierras en Atarjea era una meta casi colectiva prácticamente desde finales del siglo XIX (Uzeta, 2005: 235), en el periodo de inestabilidad enmarcado entre 1920 y 1940 surgieron ahí y en toda la Sierra numerosos líderes inclinados por la petición de ejidos en sus modalidades de restitución o dotación. La debacle de los trabajos mineros, las limitaciones laborales y la oposición de las haciendas renteras de la zona también contribuyeron a ello. Estos peticionarios, apoyados y precariamente armados desde el gobierno guanajuatense, no sólo se hicieron con el control de los ayuntamientos sino que llegaron a representar al Estado en su lucha armada contra los cristeros, encabezándola inicialmente y luego subordinándose a las fuerzas militares federales. Los vaivenes de esta guerra, con sus desplazamientos de efectivos y las tomas y abandonos de plazas por parte de ambos bandos, contribuyeron fuertemente a la generación de relaciones de amistad, fidelidad y parentesco entre los líderes agraristas de los municipios colindantes de Xichú y Atarjea. El más representativo fue el matrimonio de Perfecto González, líder agrarista de Xichú, con la hermana de Guadalupe Hernández, quién entonces encabezaba a los peticionarios de varias localidades atarjenses.

Conviene esbozar con mayor precisión las redes parentales de Guadalupe Hernández, "tío Lupe", porque a través de ellas se realizaban los enlaces entre ranchos y peticionarios de tierra. Asentado en la localidad de Aldama, Guadalupe tenía amistad con Baciliso Sáenz, líder de El Charco, a su vez con una amplia parentela diseminada en varias localidades atarjenses, y con Gregorio Jiménez, jefe de San Antón y muy amigo de Silverio Monroy, quien encabezaba el agrarismo en El Banco (Guerrero Tarquín, 1988: 233, 255, 263). Además, una hermana de Guadalupe se casó con Luis Velázquez, líder de peticionarios de la cabecera de Atarjea luego de la muerte de los integrantes del Comité Preparatorio Agrícola, uno de ellos asesinado por cristeros de la región. En su momento todos ellos fueron parte de las fuerzas rurales militarizadas formadas desde la década de 1920 como avanzadas agraristas en la Sierra, incluso Gregorio se desempeñó como escolta de las brigadas de ingenieros involucrados en el deslinde de los terrenos ejidales, cuyo primer fruto fue el ejido provisional de Atarjea en 1924. Guadalupe, Baciliso, Gregorio, Luis y Silverio fueron también comisariados de sus respectivos ejidos y, con excepción del último, presidentes municipales de Atarjea.

Como señalé previamente, una de las hermanas de Guadalupe Hernández se casó con el xichulense Perfecto González, líder agrarista de su municipio, jefe de fuerzas rurales y paralelamente cabeza de la junta municipal. La descendencia de Perfecto se afincó en Xichú, pero su numerosa parentela en ambos municipios representó un recurso político importante para consolidar el dominio del agrarismo en el interior serrano; también contribuyeron a ellos su amistad con destacadas familias xichulenses con intereses ejidales y sólidos desempeños comerciales y productivos (caña y piloncillo), como los Alvarado y los Solano.

En el contexto de esas relaciones se logró y llevó a cabola entrega de tierras en Atarjea, misma que mantuvo la dotación de armamento y la organización militarizada de los nuevos ejidatarios. Originalmente considerado como un mineral, Atarjea pasó a convertirse en un municipio ejidal ya que prácticamente toda su superficie fue repartida en una docena de ejidos, sólo un par de ellos con más de un ciento de miembros y los restantes con alrededor de una treintena, pero todos perfilados mayormente a la producción de autoconsumo. Aunque la lucha por la tierra y la obtención de ejidos supuso esfuerzos diferenciales entre los peticionarios (pues no todos tenían el mismo interés en las tierras), las parentelas cobran relevancia política precisamente aquí. El papel que jugaron los líderes locales mencionados fue fundamental no sólo por el conocimiento burocrático y los contactos que adquirieron, sino porque fue a través de ellos que las tierras llegaron a los aparceros —sus propios parientes-y que las comunidades ejidales se 
constituyeron como grupo político y prácticamente como instituciones de gobierno. ${ }^{4}$

El papel de los jefes locales fue potenciado por los nexos de amistad y lealtad política trazada con uno de los intermediarios regionales más importantes de toda la Sierra, Alfredo Guerrero Tarquín, asentado en San Luis de la Paz, uno de los municipios guanajuatenses política y económicamente más destacados de la Sierra. Aunque Tarquín tuvo amistad personal con Guadalupe, con Baciliso, con Gregorio y con otros caciques atarjenses como Agapito Flores y Rafael García, el canal para formalizar los acuerdos políticos, ejidales y municipales fue el xichulense Perfecto González. Como contrapeso a esta influencia, otro importante líder regional —-Luis Ferro Medina - radicado en el municipio de San José Iturbide, también logró entablar sólidas relaciones políticas con algunos destacados peticionarios atarjenses, entre ellos Luis Velázquez, inconforme con las mediciones realizadas por los ingenieros de Tarquín. Ambos personajes estaban involucrados con la construcción de diversas Ligas Agrarias y con lo que después serían la Confederación Nacional Campesina (CNC) y el Partido Revolucionario Institucional (PRI). Fueron estos nexos personales, por cierto longevos, los que permitieron administrar las numerosas tensiones producidas por la sobreposición de linderos entre ejidos al tiempo que generaban una jerarquía espacial definida sobre bases políticas - no económicas ni religiosas - acotada únicamente a la vertiente serrana guanajuatense.

Así, los vínculos trazados al calor de la lucha por las tierras, y que en su mejor momento enlazaron parentelas completas con los propios gobernadores a través de Guerrero Tarquín y Ferro, redefinieron el espacio público local. Si durante el predominio de la minería existieron grupos opositores capaces de disputar la dirección del municipio a la empresa, y de organizarse y demandar al Estado su intervención para limitar lo que consideraban abusos de aquella, durante el predominio ejidal todos los asuntos de interés público encontraron su lugar en las asambleas ejidales y en la comunicación con los intermediarios regionales. Es decir, en lo que sería "el partido", el PRI. El municipio fue entonces manejado por "los caciques", jefes de parentela que intercambiaban puestos administrativos y de dirección municipal de acuerdo con los líderes agraristas regionales bajo un modelo político formal de democracia electoral, con elecciones y ciudadanos participantes. La presidencia municipal y todos los cargos civiles asociados se convirtieron así en una extensión de organizaciones ejidales bajo el control de los caciques. Del mismo modo las ligas agrarias adquirieron relevancia como vías para la solicitud y promoción de servicios y obra pública que en otras circunstancias habrían sido de competencia exclusivamente municipal.

Físicamente las expresiones más notables del dominio ejidal fueron la ruina de la infraestructura minera, la demolición de algunos edificios en el centro de Atarjea, la reasignación de lotes abandonados en beneficio de algunos ejidatarios, y el trazo de un pequeñísimo jardín. Nunca se logró un mercado público pero sí eventualmente una pequeña estación de camiones, algunas tiendas de abarrotes y herramientas, y la pavimentación de las dos o tres calles que la estrecha geografía de la cañada atarjense permite. La cabecera, en donde se ubican las oficinas municipales y la parroquia, obtuvo entonces cierto perfil de centro administrativo.

Por lo que refiere a "la centralización de poder político y económico dentro de las comunidades y la asociación de dicho poder con el Estado", se podría hablar de una variante mestiza y muy peculiar de lo que se ha identificado como una comunidad revolucionaria institucional (Rus, 2002: 252); sin embargo, para este caso el término más elocuente es el de formación de una "ciudadanía posrevolucionaria" de facto (Baitenmann, 2007: 81), originada por el acceso a las parcelas ejidales mediante los vínculos de parentela. Quienes por convicción o por ausencia de vínculos no accedieron a la tierra tuvieron oportunidades laborales 
restringidas: el pequeño comercio (ya controlado por algunos caciques), la pequeña ganadería, su enganche como jornaleros fuera del municipio, o la migración definitiva. Todos ellos se encontraron fuera de las redes agraristas en las que se definía la administración pública.

Sin renunciar a su influencia dentro de sus ejidos, los caciques se desempeñaban como funcionarios municipales en cada periodo yendo de la presidencia al ministerio público, al puesto de secretario del alcalde, a las regidurías, etcétera. Prácticamente hasta la década de 1980 esa fue una prerrogativa de los dirigentes ejidales - o un "deber" y una "obligación”, como señalan algunos viejos caciques - definida en comunicación con los líderes agraristas xichulenses y con los intermediarios cenecistas, único sector del PRI local por décadas. En términos del espacio público lo más relevante fue que gracias a esos arreglos lograron administrar las irresolubles pugnas por linderos ejidales y que lograron anular la presencia política y pública del sacerdote. Hay que decir algo más a este respecto.

Abandonada durante el periodo cristero, la parroquia volvió a ser ocupada en la década de 1940 ganando presencia mediante algunas actividades rituales ligadas con la liturgia católica. El punto culminante de ese proceso de rehabilitación eclesial en Atarjea está bien retratado en una viva anécdota contada con diferentes matices por muchos de los viejos militantes agraristas. Se trata de la celebración a la virgen el 12 de diciembre de 1952, centrada en una peregrinación hacia una imagen "natural" de la guadalupana cerca de una de las localidades ejidales más importantes del municipio, Aldama. Organizada conjuntamente entre la presidencia municipal y la parroquia, esas celebraciones solían terminar en una romería con numerosos y violentos alcoholizados. En aquella fecha el párroco y el alcalde - Gregorio Jiménez- acordaron conjuntamente desautorizar la venta de alcohol en el punto referido. Ambos personajes representaban una serie de valores localmente destacados: los dos eran conocidos por ser personas "activas" y de carácter, con rasgos de altivez y dominio que incluían su gusto por las armas y por las mujeres: "me muero con el que sea, con cuchillo o con pistola", recuerdan haberle escuchado decir al cura. El edil, en tanto, era un patriarca y un cacique en su ejido (San Antón); había participado como agrarista militante al lado de su amigo Guadalupe Hernández y había destacado en las décadas turbias y armadas del reparto agrario.

El incumplimiento de la prohibición por el propio alcalde derivó ahí mismo en un enfrentamiento entre éste y el cura, con apoyos mezclados de los peregrinos, que estuvo a punto de terminar en balacera. A raíz de esto se generó un pequeño movimiento encabezado por el párrocoy apoyado por los vecinos menos favorecidos y con menos vínculos con las parentelas ejidales; el movimiento presionó al gobierno del estado para la destitución del presidente municipal, quien luego de entrevistarse con el ejecutivo estatal recibió un apoyo determinante: el gobernador aseguró a los inconformes que carecía de autoridad constitucional para separar a un alcalde de su puesto. Esta confrontación y la preeminencia de un espacio público definido alrededor de líderes agraristas, depurado además de influencias religiosas, concluyó cuando el párroco desapareció del lugar llevándose a una muchacha a la que luego, dicen, embarazó y abandonó. Sus sucesores se limitaron estrictamente a las labores eclesiales mientras las expresiones públicas de religiosidad transmutaron en prácticas "tradicionales" sin mayores referencias políticas.

No fueron las prácticas ni el uso del espacio los que cambiaron pero sí su sentido al modificarse las relaciones entre los participantes. En paralelo, la formación de alianzas y acuerdos de cara a la definición de las planillas y sus candidatos al ayuntamiento se mantuvieron en las manos de los caciques y sus parentelas. El ámbito de estas negociaciones fueron las casas ejidales (o del campesino), donde los ejidatarios de cada localidad discutían sus problemas agrarios al igual que la vida política del municipio. 


\section{Diversificación y rupturas}

Entre la década de 1960 y el fin de siglo la sociedad rural devino más compleja gracias a la estabilidad política en la entidad y a la introducción lenta pero constante de servicios e infraestructura. En diferentes localidades atarjenses lograron consolidarse algunos comerciantes (varios de ellos también ejidatarios) pese a que el municipio se mantenía rural y pobre, ${ }^{5}$ y surgieron actores como los maestros a partir de docentes inmigrantes y de los hijos e hijas de dirigentes ejidales que pudieron cursar estudios magisteriales. Eventualmente asomaron también migrantes y algunos profesionistas, todos ellos con intereses y necesidades que trascendían los marcos ejidales: caminos, puentes, servicios médicos, escuelas, luz y agua potable, etcétera. No obstante la vida política municipal seguía definiéndose dentro del PRI, que para ello incluyó junto con el sector campesino cenecista al sector popular desde 1951 (la CNOP), a un pequeño sector de ganaderos en los años sesenta, y a partir de la década de 1980 al Frente Juvenil Revolucionario. En el paso a la siguiente década la CNOP impulsó intermitentemente organizaciones femeninas con cierto éxito. ${ }^{6}$

Dependiendo de las alianzas y los vínculos con las fuerzas políticas de la entidad, en varios momentos las planillas al ayuntamiento fueron encabezadas por maestros o jóvenes desligados de las organizaciones ejidales pero con relaciones de parentesco y amistad entre ellos. ${ }^{7}$ De hecho las autoridades electas negociaban todas las plazas municipales ubicando en puestos de bajo perfil pero de remuneración segura ( $v$.g. la casa de la cultura, la oficina de intendencia) a los viejos patriarcas de sus parentelas de procedencia, una maniobra que entremezclaba el sentimiento de afecto y gratitud y la búsqueda de tranquilidad política. La administración pública se reconfiguraba así sin que existieran rupturas en la lógica predominante de las parentelas, es decir, aunque en buena medida el ámbito político seguía definido por los efectos organizativos del reparto agrario, el vínculo entre las parentelas y los ejidos dejó de ser el elemento principal para la definición local de ciudadanía y para la participación política. Sin salir del ámbito priísta, los parentescos políticos comenzaron a rebasar los cauces ejidales simultáneamente al relevo generacional, al declive y muerte en los años setenta y ochenta de los líderes regionales Ferro y Guerrero Tarquín, y a la disolución de las relaciones políticas con los González, que enfrentaron el ocaso de su dominio en Xichú. De hecho fue en 1976 cuando estas redes estuvieron comprometidas en su última labor política acarreando contingentes campesinos para el multitudinario mitin político del candidato presidencial López Portillo en un municipio queretano colindante.

Tras la reforma municipal impulsada desde el ejecutivo federal por Miguel de la Madrid, los puestos en el ayuntamiento comenzaron a ser bien remunerados, lo que constituyó un aliciente para la competencia por ellos. Otros procesos e iniciativas estatales también cimbraron la vida política local pese a que no lograron romper las fidelidades con el PRI. El progresivo abandono del proyecto agrarista por parte del Estado tuvo su cenit en 1992 con la modificación al artículo 27 constitucional y con la posterior aplicación del Programa de Certificación de Derechos Ejidales y Titulación de Solares (PROCEDE), que reintrodujo en el municipio una racionalidad privatizadora y de compra-venta de tierra. Eso y la peculiar manera en que el Partido Acción Nacional (PAN) arribó a la gubernatura de la entidad en 1991, que ha mantenido hasta hoy, mellaron aún más la autoridad y el peso de los ejidos y de los viejos ejidatarios en Atarjea. Es necesario detenerse en estos dos asuntos por su fuerte impacto en la reorganización del espacio público.

\section{PROCEDE}

El gobierno de Salinas de Gortari (1988-1994) impulsó dos programas de fuerte impacto social en zonas rurales que se sumaron a diversos programas de menor empuje bajo responsabilidad de la Comisión Nacional de Zonas 
Áridas. El primero fueron los Fondos Regionales de Solidaridad, el segundo fue el PROCEDE.

En el noreste de Guanajuato buena parte de los Fondos Regionales quedaron a cargo del Instituto Nacional Indigenista (INI) bajo el argumento de que en esa zona se ubicaban las relativamente pocas comunidades indígenas reconocidas por el gobierno del estado, zonas además de fuerte marginación. Pese a no ser considerada como parte de la zona indígena, el Centro Coordinador Indigenista del INI (con sede en San Luis de la Paz) impulsó en Atarjea varios proyectos entre 1991 y 1998 como parte de un plan para ampliar su radio de influencia en la zona otomí chichimeca (INI, s/f): tienda de abastos, introducción de ovinos, compra de máquinas de coser, adquisición de caprinos, rehabilitación de acequias, compra de motobombas, acopio y comercialización de orégano, y recursos para el molino de nixtamal y el taller de costura. Lo restringido de los apoyos generó un impacto limitado, no repercutió en la organización política interna posiblemente por lo acotado e irregular de los mismos y quizá también porque muchos de los jóvenes ya tenían cierta presencia en el PRI o estaban involucrados en la definición de circuitos migratorios internacionales.

Sin embargo a inicio de 1993 asomó en todo el municipio el PROCEDE, que preveía el reconocimiento de las parcelas ejidales como propiedades privadas introducidas al mercado. ${ }^{8}$ De acuerdo con algunos autores, en muchas localidades rurales el PROCEDE y las modificaciones constitucionales "reactivaron luchas agrarias y viejos conflictos" (Stephen, 1998: 27). En un municipio comprometido con la construcción de comunidades campesinas y en donde los límites interejidales fueron mal trazados desde el inicio este programa reactivó la memoria del reparto y generó suspicacias entre localidades abonando expresiones de rechazo a su ejecución. Su aplicación fue muy resistida en Atarjea y en todo Xichú, pues muchos ejidatarios consideraban que con los deslindes parcelarios la superficie de su ejido se vería injustamente afectada.
Aún hoy es común escuchar expresiones que asocian al PROCEDE y a su sucesor, el Fondo de Apoyo a Núcleos Agrarios sin Regularizar, con la expropiación y venta de tierras. Además, frente a migrantes con cierta capacidad adquisitiva, estas disposiciones han sido comprendidas como la posibilidad de concentración de tierra en pocas manos: un regreso a la época preagrarista.

Sin embargo el perfil de este programa logró beneficiarse de las diferencias que estuvieron en la base del reparto agrario tramitado desde los años veinte y realizado en 1937: excepto los ejidos del entorno de la cabecera municipal que aspiraban a la restitución los demás solicitaron directamente la dotación. ${ }^{9}$ Es decir, la relación que los fundadores de esos ejidos tenían con la tierra era distinta de quienes argumentaban una propiedad histórica. En los ejidos con dotación definitiva PROCEDE no despertó tantas animadversiones, incluso logró realizar trabajos de medición y entrega de planos. En los que infructuosamente solicitaron restitución, que además son ejidos con problemas de linderos y por tanto sin dotación definitiva aún, el programa redimensionó la figura del comisariado ejidal montado en la oposición a la escrituración individual.

Varios de estos comisariados enviaron cartas al presidente de la república, Vicente Fox, para que interviniera en su favor y en contra de los funcionarios agrarios que insistían en la introducción del programa. Para su desconcierto, la presidencia reenviaba esos documentos precisamente a las oficinas de los funcionarios que querían evitar. En simultáneo, el programa mostró también el absoluto distanciamiento entre el "sector" agrario y los sucesivos presidentes municipales. Estos últimos - algunos ya sin relación directa con los ejidos - se limitaron a apoyar a los técnicos del programa enviando elementos de la seguridad pública del municipio o a personal del ayuntamiento para evitar algún problema cuando se realizaban mediciones. Resultaba claro que la asociación de un poder local centralizado con el Estado ya no existía, al menos no a través de las organizaciones ejidales. 
Las expresiones de oposición, no compartidas por todos los ejidos, revelan la introducción del PROCEDE y sucesores como proyectos estatales no consensados localmente. Su paulatino avance hace evidente la ausencia de mediaciones regionales capaces de administrar con efectividad los conflictos tal como lo hicieron Guerrero Tarquín y Ferro durante buena parte del siglo pasado: a través de relaciones de amistad y lealtad con redes de parentelas.

En síntesis, la reacción ante el PROCEDE, con la ausencia de mediaciones políticas efectivas para enfrentarlo y con el repunte del papel político de algunos comisariados ejidales, son expresión del desplazamiento de los asuntos agrarios dentro del espacio público municipal, o bien de la reconfiguración de un espacio público disociado del predominio ejidal. Pero esto no significa la marginación de las parentelas de eseámbito; si bien los viejos caciques ya habían muerto y algunos de sus hijos habían sido desplazados, la política municipal seguía siendo el escenario para esas redes. Lo veremos en el siguiente inciso.

\section{Elecciones}

Durante el dominio ejidal las prácticas electorales se mantuvieron subordinadas a los vínculos políticos regionales. Se trataba de elecciones no competidas en donde los ciudadanos posrevolucionarios sólo refrendaban los acuerdos tomados dentro del sector campesino priista. ${ }^{10}$ Las planillas en competencia - por lo común dos - se integraban a partir de un cacique o un hijo de cacique con parientes y amigos perfilados a la sindicatura y a las regidurías. Cuando se definía el nombre del candidato la sindicatura quedaba en manos del precandidato perdedor y las regidurías se repartían entre las planillas; entonces los puestos municipales se negociaban entre todas las nuevas autoridades, así que había lugar para acomodar a líderes ejidales. Como he señalado, esto comenzó a cambiar con la incorporación de otros sectores al PRI, pero también gracias al activismo de algunos profesores inmigrantes que organizaron lo que sería el PAN atarjense junto con algunos pocos militantes radicados fuera de la cabecera.

En 1991, luego de unas elecciones estatales muy cuestionadas y un arreglo poco claro con el entonces presidente Salinas de Gortari, el partido Acción Nacional se hizo con la gubernatura en la entidad. Facilitando el trabajo de asociaciones civiles permeadas por ideologías individualistas centradas en la "persona" más que en la comunidad (como Desarrollo Rural de Guanajuato), el gobierno de la entidad comenzó a ser un referente para el fortalecimiento de nuevos grupos organizados en muchos municipios. Tanto el gobernador Medina Plascencia como Vicente Fox en sus dos candidaturas (1991,1995), durante su gubernatura (1995-1999), hicieron presencia en Atarjea teniendo trato institucional con las autoridades pero también haciendo proselitismo al acercarse a ex alcaldes que mantenían ciertas bases sociales no sólo a partir de sus propias parentelas sino también del éxito de gestiones y de distribución de apoyos federales durante sus administraciones. Estos esfuerzos rindieron frutos paulatinamente, llevando incluso a que connotados ejidatarios - en su momento priistas que habían sido autoridades municipales- se sumaran al PAN.

Fue en esos años que el PROCEDE asomó en todo el municipio. Por contradictorio que parezca en el plano ideológico, la consolidación de Acción Nacional en el municipio es comprensible en ese contexto de tensión $\mathrm{y}$ de diferencias de fondo entre los ejidos.

Además, como un efecto retardado de la escisión que el priismo nacional experimentó en 1988, algunos maestros y viejos ejidatarios desplazados por jóvenes más preparados y ambiciosos se agruparon sin mucha fortuna bajo las siglas del PRD. Lo relevante de esta reorganización política no fue sólo la construcción de un ámbito que se perfilaba hacia encuentros electorales realmente competidos sino, por una parte, la constancia de grupos de descendencia que remontaban su legitimidad a los fundadores de los ejidos (sus 
abuelos o padres) y que mantuvieron el control del municipio bajo el PRI hasta las elecciones de 2006; y, por otra, la redefinición de las tensiones en términos de las localidades enfrentadas con la cabecera, asiento de algunas de las parentelas dominantes y en donde supuestamente tenían mayor destino los pocos recursos estatales y federales canalizados al municipio.

Así, los espacios comunes adquirieron una mayor apertura. Las casas ejidales, que era donde se recibía a los candidatos a la alcaldía y se negociaban las alianzas municipales, decayeron como espacios de gobierno y referentes simbólicos. El auditorio municipal, las canchas deportivas e incluso las escuelas de las distintas localidades fueron promovidas como espacios asociados con una participación "ciudadana" no constreñida por los intereses ejidales. Durante las campañas electorales de la década de 1990 se produjeron los primeros mítines opositores concurridos, lo mismo que algunas marchas en las calles de la cabecera y las primeras protestas postcomiciales, incluso una de ellas con una caravana a la capital de la entidad alegando fraude electoral.

Como parte de este efecto las opciones de patronazgo fuera del alicaído ámbito agrario y ejidal encontraron nuevos caminos en los partidos y en la capacidad de gestoría de sus agentes. Entonces los apoyos federales fueron identificados con el PRI hasta el año en que ese partido perdió la presidencia de la república, y los apoyos del gobierno de la entidad fueron asociados con el panismo. En este contexto las negociaciones para definir al candidato del PRI a la alcaldía se hicieron cada vez más ríspidas entre las parentelas más destacadas hasta llegar a una gran ruptura encabezada por Néstor Galindo, ${ }^{11}$ un joven aspirante de perfil peculiar (ejidatario, licenciado en derecho, y ex-alcalde priista), enfrentado contra Fernando Lozano, edil saliente y profesionista inmigrante, y contra Adrián Fernández, uno de los caciques locales que además de ejidatario había sido profesor, comerciante y mentor político de Néstor. La genealogía de estas personas, avecindados en la cabecera de Atarjea y respectivamente sobrino, cuñado y tío, es elocuente por lo que respecta a su raigambre y origen político: descienden de Florentino Leal, que encabezó la lucha por la tierra a finales del siglo XIX contra la empresa minera que las detentaba, y que fue líder agrarista de Mangas Cuatas y fuerte influencia en el ejido de Atarjea. La parentela de los Fernández incluye al menos a tres miembros identificados localmente como caciques -dos amigos de Tarquín entre ellos-y a cinco más que han desempeñado cargos importantes tanto en los ejidos de Atarjea y Mangas Cuatas como en la presidencia municipal.

La disputa entre estos tres personajes se dirimió parcialmente en la votación entre la militancia municipal del PRI para elegir a su candidato y tuvo conatos de enfrentamiento por la supuesta instalación ilegal de una casilla, además del acarreo de votantes y las acusaciones nunca confirmadas de compra de votos. El resultado desfavorable llevó a Néstor a renunciar al PRI incluso después de entrevistas con sus familiares, quienes le aseguraban puestos en el ayuntamiento entrante. Su renuncia le permitió fundar al vapor al Partido Verde Ecologista Mexicano (PVEM) en Atarjea. La presencia de esta nueva asociación, y la reorganización de una parentela prominente provocaron que el PRI cayera en las elecciones de 2006 por debajo del PVEM y del PAN, que inopinadamente triunfó por una diferencia de tan sólo cuatro votos en medio de una enorme tensión. Los calificativos de "malagradecido", "ambicioso", "interesado", que le adjudicaron a Néstor cuando se distanció de su tío, sumados a la ruptura de todos los implicados (que incluye el retiro de la palabra entre esposas, madres y hermanas) han puesto a prueba los sentimientos de cercanía de esta parentela.

En lo sucesivo el espacio público se transformó en un ámbito de proselitismo para el nuevo partido, de reorganización opositora de los priistas asentados en torno de la cabecera municipal y de los Fernández, y de mayor avance de las redes de parentesco afincadas en las localidades circundantes y asociadas con el PAN. Con ese clima político debió enfrentarse un nuevo 
proyecto federal, tan impopular como el PROCEDE y que por su importancia deberá ser abordado en otro texto: el decreto de creación de la Reserva de la Biosfera Sierra Gorda de Guanajuato, que incluye a buena parte de Atarjea y cuyo perímetro afecta a varios de sus ejidos cruzando por encima de otros. Las comunidades ejidales directamente implicadas resintieron la andanada de restricciones en el uso del medio que el decreto señala; en las afectadas parcialmente se generaron perspectivas encontradas y en los ejidos no involucrados las posiciones fueron semejantes a los de los sectores ajenos al trabajo agrícola: el decreto les resultaba positivo porque "no nos afecta" y porque sugiere la posibilidad de intercambios, apoyos y recursos para proyectos de diversa índole.

El decreto, además, posicionó favorablemente a nuevas instituciones regionales, como la dirección de la propia Reserva y a las asociaciones civiles que pronto comenzaron a concursar por recursos que aquella ofrece para la promoción y realización de proyectos de corte ecologista. Los montos para obras constituyeron un aliciente para una administración que obtuvo el ayuntamiento con pocos votos de diferencia y que inició con un fuerte déficit por razones que tuvieron que ver con liquidaciones y reasignación de los cargos municipales a las redes de parentesco y amistad de las nuevas autoridades. Con esto el espacio público dio un enorme giro: los nuevos actores están pugnando porque la protección del entorno, hasta antes poco relevante, sea el problema colectivo que articule la acción de la ciudadanía municipal y de sus grupos organizados.

\section{Conclusión}

En este texto he buscado mostrar los vínculos entre sentidos locales de parentela y formación de ciudadanías posrevolucionarias con la definición de un espacio público transformado por la emergencia de actores desvinculados de los ejidos, por proyectos estatales antiejidales y por elecciones realmente competidas. En Atarjea el espacio público estuvo comprometido durante largas décadas con mediaciones políticas muy efectivas, que contribuyeron al trazo de una jerarquía de localidades mediante la relación de líderes regionales con patriarcas locales. Esto tuvo repercusión inclusive en la reorientación de los espacios físicos.

La diversificación social, política y económica, comenzó a minar una forma de organización contenida en el marco de los ejidos y, un poco más ampliamente, en el priismo dominado por el sector campesino. Las metas identificadas bajo el dominio centralizado de varios grupos de parentesco como justas (entre ellas la garantía en el acceso a la tierra, la búsqueda de apoyos a la producción agropecuaria, y el ajuste de linderos), se debilitaron frente a los nuevos programas estatales $y$ ante nuevos actores locales con perspectivas propias. Los problemas agrarios dejaron de formar parte de los intereses comunes, dejaron de ser también los dominantes. La ciudadanía posrevolucionaria entró en crisis frente a un tipo de ciudadanía tendencialmente liberal, más involucrada en competencias de sufragio y menos en la lucha corporativa contra las condiciones de desigualdad.

Las elecciones realmente competidas han contribuido a hacer del espacio público un ámbito "físicamente abierto", en donde las diversas expresiones políticas y sociales tienen libre cabida. Sin embargo, se trata menos de un ámbito de ciudadanos que se mueven a partir de intereses individuales y más de uno en donde las parentelas, las amistades y vecindades se han realineado justamente a partir de coyunturas de sufragio transformadas en momentos de alta tensión social. En la ciudadanía local se han mezclado de manera imprevista los sentidos de parentela, los rencores entre localidades y, también, nociones de intercambio actualizadas a través de proyectos estatales diferencialmente confrontados.

En esto hay una paradoja, y es que se acrecienta la debilidad de los grupos corporados ejidales en un 
municipio absolutamente rural haciendo avanzar proyectos antiagraristas y poco populares. Así, a mayor apertura del espacio público mayor desplazamiento de los ejidos como agrupaciones políticamente trascendentes y mayor posibilidad de avance, no consensado, de iniciativas y proyectos estatales. En términos discursivos se trata de la construcción local de ciudadanías liberales; en términos concretos, de la pérdida de consistencia de metas comunales agrarias y, en consecuencia, de la diversificación y debilitamiento de actores políticos que pese a eso buscan reinterpretar con sus propias claves - v.g. el sentido de parentela - el avance de modelos cívicos anclados en el individuo.

\section{Notas}

'Agradezco a tres anónimos dictaminadores los comentarios y múltiples sugerencias realizados a una versión previa de este artículo. Me fueron de gran utilidad.

2 Autores entusiastas de la sociedad liberal, como John Rawls, han asociado el importante e inherente correlato de justicia y moral de todo este asunto con el racionalismo electivo (Gargarella, 1999).

3 Entre las unidades de parentesco que Friedrich identificó en su estudio clásico de Naranja hay un par que tienen coincidencias con la noción de parentela: la "familia ejidal", que gira en torno a parientes con derechos parcelarios, y sobre todo la "familia política", que llega a funcionar como facción aglutinando a compadres, amigos y parientes bilaterales a partir de un ego con experiencia y posicionamiento social (Friedrich, 1991: 162, 167).

${ }^{4}$ Los padrones de peticionarios resguardados en el Archivo del Registro Agrario Nacional, en la ciudad de Guanajuato, muestran con bastante claridad la reiteración de apellidos y los parentescos de los líderes.

${ }^{5}$ La generación de recursos propios era escasa. El rubro más importante fue el impuesto por marca de fierros al ganado, derecho que después de una reforma administrativa en la entidad fue trasladado de los municipios al dominio del gobierno guanajuatense. Eso ocurrió a inicios de la década de 1960.

${ }^{6}$ Alrededor de 1988 la CNOP se comprometió con el Movimiento Nacional de la Mujer. El CEN del PRI guanajuatense lo promovió en los municipios del noreste de la entidad, de donde surgieron un par de presidentas municipales, una en el municipio de Tierra Blanca y otra precisamente en el de Atarjea.

${ }^{7}$ Aquí destacan los hijos de los caciques Rafael García, Juan Hernández, Jesús Díaz, Agapito Flores. Los hijos de los tres primeros más vinculados con el magisterio que con el ejido, el hijo del último un exitoso comerciante, ejidatario y maestro que heredó el liderazgo de su padre. Entre esta camada hay que destacar a Javier Montes, comerciante sin ningún vínculo ejidal (su abuelo era prestamista local) que llegó a la presidencia municipal a través de la CNOP en 1974.

${ }^{8}$ En su definición se apunta que el "objetivo principal del Programa es dar certidumbre jurídica a la tenencia de la tierra a través de la entrega de certificados parcelarios y/o certificados de derechos de uso común, o ambos según sea el caso, así como de los títulos de solares en favor de los individuos con derechos que integran los núcleos agrarios que así lo aprueben y soliciten" (Procuraduría, 2004). Las autoridades agrarias nunca olvidan señalar el sentido privatizador de los certificados: en un encuentro de marzo de 2008 en el que se destacó que en Guanajuato faltaban certificar alrededor de 80 ejidos concentrados en una zona de conflicto por traslapes de linderos (precisamente en Atarjea y Xichú), el titular del Registro Agrario Nacional señaló que la certificación provee de seguridad jurídica tanto a viviendas como a parcelas "y se puede heredar o venderlo y pueden ingresar a programas" (Sánchez, 2008: 3). Poco después el secretario de la Reforma Agraria lo definió de manera similar en una entrega de certificados parcelarios en cinco ejidos de Xichú: "Ustedes son ejemplo de cómo se hace justicia en el campo [...], se determinó la 
pertenencia de la tierra [...] hoy las parcelas que han estado trabajando llevan nombre y apellido [...]. Lo más importante es que ustedes van a seguir siendo ejidatarios hasta que ustedes mismos así lo decidan" (RAN, 2008: 1).

${ }^{9}$ Entre los que buscaron la restitución están Atarjea, Mangas Cuatas, El Banco, El Charco, San Antón, El Toro; los restantes son El Durazno, El Carricillo, La Joya, Los Álamos y los Llanitos, Aldama, El Salitrillo.

${ }^{10}$ Cuando señalo que no había votaciones competidas me refiero a que el candidato - $y$ presidente entranteya había sido definido de antemano por acuerdo entre las parentelas locales, los intermediarios regionales y el Comité Ejecutivo Estatal del PRI. Las votaciones tan sólo refrendaban decisiones ya tomadas, de ahí que hasta 1988 los resultados electorales municipales señalan que $100 \%$ de los votos emitidos fueron para ese partido, el único en el municipio. En la década de 1990 emergieron localmente el PAN y el PRD con gente ajena a los ejidos o con viejos ejidatarios desplazados; fue hasta las elecciones de 1997 que hubo una competencia real entre el PAN y el PRI, con $45.8 \%$ y $50.7 \%$ de los votos respectivamente, lo que repercutió notablemente en la conformación del ayuntamiento. Fuente: Sistema Electoral Mexicano, Instituto de Mercadotecnia y Opinión, SIEM/ IMO (http://www.imcorp.com.mx).

${ }^{11}$ Los nombres que utilizo en este inciso son seudónimos.

\section{Bibliografía}

Baitenmann, Helga (2007), "Reforma agraria y ciudadanía en el México del siglo XX”, en Francisco Javier González Carpinteiro (editor), Paisajes mexicanos de la reforma agraria. Homenaje a W. Roseberry, México: El Colegio de Michoacán-BUAP-CONACYT, pp. 71-95.

Boissevain, Jeremy (1974), Friends of Friends. Networks, Manipulators and Coaltions, New York, Basil: Blackwell, St.Martin's Press.

Escalante Gonzalbo, Fernando (1995), Ciudadanos imaginarios, México: El Colegio de México.
Friedrich, Paul (1991), Los principes de Naranja. Un ensayo de método antropohistórico, México: Enlace Grijalbo.

Gargarella, Roberto (1999), Las teorías de la justicia después de Rawls. Un breve manual de filosofía politica, España: Paidós.

Guerrero Tarquín, Alfredo (1988), Reminiscencias e un viaje a través de la Sierra Gorda, México: INAH.

Habermas, Jürgen (1991), The Structural Transformation of the Public Sphere. An Inquiry into a Category of Bourgeois Society, translated by Thomas Burger with the assistance of Frederick Lawrence, Cambridge Massachusetts: The MIT Press.

Harvey, Neil (2000), La rebelión de Chiapas. La lucha por la tierra y la democracia, México: Era.

INI ( $\sin$ fecha), "Identificación de la región ChichimecaOtomí", en Mecanoescrito, México.

Procuraduría Agraria (2004), "PROCEDE”, www.pa.gob. $\mathrm{mx} /$ Procede/info_procede.htm, [29 de agosto de 2008].

Rabotnikof, Nora (1997), El espacio público y la democracia moderna, México: Instituto Federal Electoral.

Registro Agrario Nacional (2008), “Comunicado", 22 de junio, México, p.l.

Reina, Leticia (1988), "La rebelión campesina de Sierra Gorda (1847-1859)", en Friedrich Katz (comp.), Revuelta, rebelión y revolución. La lucha rural en México del siglo XVI al siglo XX, vol. 2, México: Editorial Era, pp.242-266.

Rhum, Michael (2000), "Parentela", en Thomas Barfield (editor), Diccionario de Antropología, México: Siglo XXI, p. 391.

Rus, Jan (2002), "La comunidad revolucionaria institucional: la subversión del gobierno indígena en los Altos de Chiapas, 1936- 1968", en Juan Pedro Viqueira y Mario Humberto Ruz (editores), Chiapas, los rumbos de otra historia, México: UNAM-CIESAS , pp. 251-277.

Salmerón Castro, Fernando I (2002), "Modernidad y prácticas políticas: democracia, eslabonamientos y mediaciones en la sociedad civil", en Revista Mexicana de Sociología, enero-marzo, vol. 64, no. 1, Instituto de 
Investigaciones Sociales, México: UNAM, pp. 31-65.

Sánchez, Guadalupe (2008), "Entregaron 89 títulos parcelarios", en El Sol del Bajío, 14 de marzo, no.1539, Guanajuato, p. 13.

Starn, Orin (1991), "Con los llanques todo barro". Reflexiones sobre rondas campesinas, protesta rural y nuevos movimientos sociales, Perú: IEP Ediciones.

Stephen, Lynn (1998), "The cultural and political dynamics of agrarian reform in Oaxaca and Chiapas", en Richard Snyder and Gabriel Torres (editors), The Future Rol of the Ejido in Rural Mexico, San Diego, La Jolla, Center for U.S.-Mexican Studios, University of California, pp. 7-30.

Uzeta, Jorge (2005), "El bien común y el bien particular en el mineral de Atarjea, Guanajuato (1871-1891)”, en
Relaciones, estudios de historia y sociedad, primavera, vol. XXVI, núm. 102, México: El Colegio de Michoacán, pp. 233-261.

Wilson, Fiona (2002), “iCiudadanos indios? La formación de una cultura política en los andes del Perú", en Marco Calderón, Willem Assies y Ton Salman (editores), Ciudadanía, cultura y reforma del Estado en América Latina, México: El Colegio de Michoacán-Instituto Electoral de Michoacán, pp.87- 101 .

Zukin, Sharon (1991), Landscapes of Power. From Detroit to Disney World, Estados Unidos: University of California Press.

\section{La Sierra Gorda}

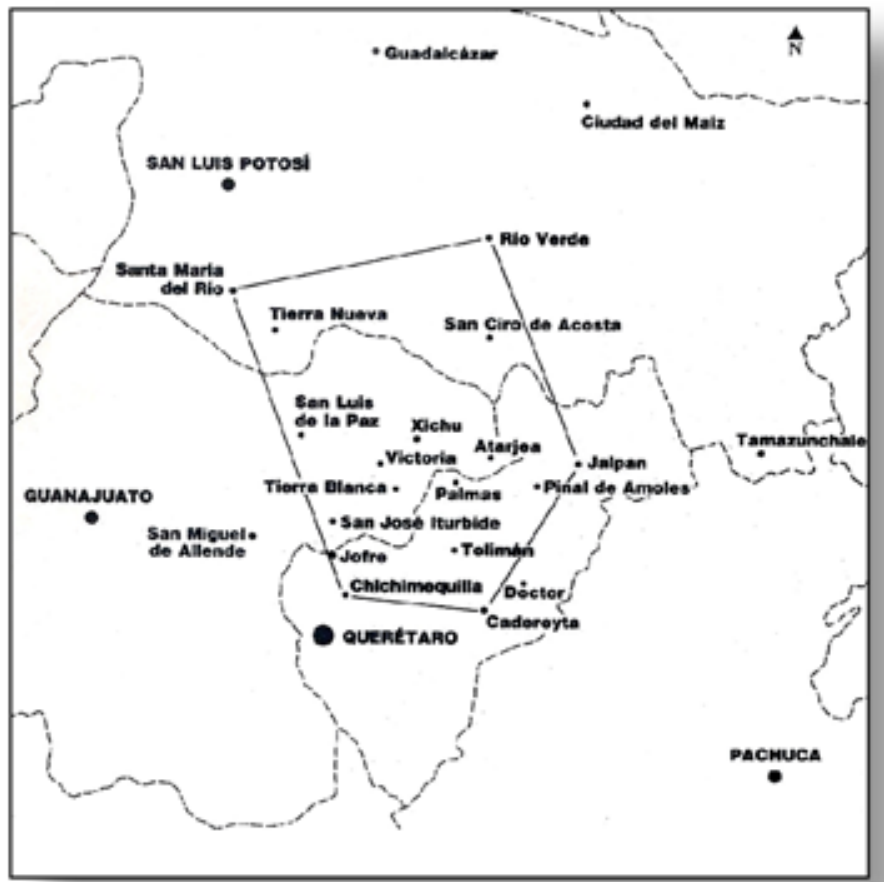

FUENTE: Tomado de Reina, 1988: 245 